\title{
MOLECULAR AND GENETIC ANALYSIS OF CHROMOSOMES X IN SACCHAROMYCES CARLSBERGENSIS
}

\author{
by
}

\author{
GREGORY PAUL CASEY
}

\author{
Department of Physiology, Carlsberg Laboratory \\ Gamle Carlsberg Vej 10, DK-2500 Copenhagen Valby
}

Present address: Department of Applied Microbiology and Food Science, University of Saskatchewan, Saskatoon, Saskatchewan S7N OWO, Canada

Keywords: Lager yeast, Saccharomyces cerevisiae, ILV3, dihydroxyacid dehydrase, isoleucine, valine, electrophoretic chromosome separation, kar mediated chromosome transfer

\begin{abstract}
Molecular hybridization of electrophoretically separated and blotted chromosomes with ILV3 gene probes detected the presence of three chromosomes X in S. carlsbergensis 244 lager yeast. Meiotic segregants, which were disomic or trisomic for chromosome $\mathrm{X}$ were crossed with a karl-l strain of S. cerevisiae (MATa or MAT a arg3 met $3 \mathrm{llv} 3 \mathrm{cycl}-1 \mathrm{cdcl} / \mathrm{hom} 6$ ade2.40 $\mathrm{cyh} 2 \mathrm{karl}-\mathrm{l}$ ) for single chromosome transfer and isolation of two of the chromosomes $\mathrm{X}$ from the lager yeast. Type I chromosome $\mathrm{X}$ migrates slower than a reference chromosome $\mathrm{X}$ of S. cerevisiae K5-5A during chromosome separation by electrophoresis and contains the allele of $I L V 3$ unique to the lager yeast. It recombines with chromosome $\mathrm{X}$ from $\mathrm{S}$. cerevisiae, but only in the left arm. Type II chromosome $\mathrm{X}$ migrates faster than the reference chromosome $\mathrm{X}$ and contains the allele of $L L V 3$ also found in $\mathrm{S}$. cerevisiae $\mathrm{S} 288 \mathrm{C}$. It recombines only in the right arm with chromosome $X$ from $\mathrm{S}$. cerevisiae. The third chromosome $X$ from $\mathrm{S}$. carlsbergensis, which co-migrates with the reference chromosome X of S. cerevisiae K5-5A, has yet to be isolated into the genetic background of a genetic standard strain.
\end{abstract}

\section{INTRODUCTION}

In Saccharomyces cerevisiae, each of the structural genes for the first four steps of the isoleucine-valine pathway have been mapped and cloned $(8,25,26,27)$. Unfortunately, knowledge obtained in studies with $\mathrm{S}$. cerevisiae yeast cannot be directly applied in experiments attempting to genetically analyze and/or engineer lager yeast strains as these yeasts generally exhibit no or poor mating ability, poor sporula- tion and low spore viability $(1,9,14,32,35)$. Attempts to overcome these difficulties have been limited by a lack of detailed knowledge concerning the genetic composition of S. carlsbergensis lager yeast. There is, however, a general belief in the brewing industry that lager yeasts are polyploid $(7,16,28,32)$ and that this property, besides interfering with mating ability, causes irregularities in meiosis that result in poor sporulation and low spore viability.

Abbreviations: EDTA = ethylene diamine tetracetic acid, sodium salt; $\mathbf{k b}=$ kilo base; NPD = non parental ditype; $\mathrm{PD}=$ parental ditype; $\mathrm{SC}=$ synthetic complete medium; $\mathrm{SD}=$ synthetic dextrose medium; $\mathrm{SDS}=$ sodium dodecyl sulphate; $\mathrm{SSC}=0.15 \mathrm{M}-\mathrm{NaCl}, 15 \mathrm{mM}-\mathrm{Na}$ citrate, $\mathrm{pH} 7.0 ; \mathrm{TE}=10 \mathrm{mM}-$ Tris $\cdot \mathrm{HCl}, 1 \mathrm{mM}-\mathrm{EDTA}, \mathrm{pH} 7.5 ;$ Tris $=$ tris-(hydroxymethyl)-amino methane; TT = tetratype; YPD = yeast extract peptone dextrose medium. 
In recent years, however, the technique of single chromosome transfer $(6,21)$ has made it possible to isolate and analyse individual wildtype chromosomes from a S. carlsbergensis lager yeast in the genetic background of a S. cerevisiae standard strain. The technique is based on the karl mutation which dramatically reduces the frequency of karyogamy after zygote formation (5) but still permits chromosome transfer between nuclei. Thus in $k a r l \times K A R 1$ crosses one or several chromosomes can be transferred between nuclei during the transient heterokaryotic state $(6,19,21)$.

In this manner chromosomes III, V, XII and XIII (with $I L V I, I L V 5$ and $I L V 2$ located on the latter three chromosomes, respectively) have been isolated and studied from a S. carlsbergensis lager yeast $(19,21,34)$. Genetic recombination and molecular hybridization experiments have been very revealing as it is now apparent that these chromosomes exist in the lager yeast in two copies. In general, one of the chromosomes is closely homologous to the same chromosome from $\mathrm{S}$. cerevisiae and can recombine extensively with it $(19,21,34)$. The second chromosome, called the homeologous chromosome, contains the same genes in the same order as those found in the S. cerevisiae and homologous S. carlsbergensis chromosomes, but it is largely unable to recombine with its counterpart S. cerevisiae chromosome. Molecular hybridization studies have shown that genes on the homeologous chromosomes have a different structure at the nucleotide sequence level than genes in the homologous chromosomes $(12,20)$. Direct evidence for this has been obtained in the case of $I L V I$ where analysis of the nucleotide sequence in a 276 base long region of the open reading frame in the $I L V I$ allele of $\mathrm{S}$. cerevisiae and the homeologous $I L V I$ allele in S. carlsbergensis has revealed only $84 \%$ sequence homology (C. GJERMANSEN, personal communication). Chromosome $\mathrm{X}$ contains the $I L V 3$ gene, encoding for dihydroxyacid dehydrase, and two alleles of this gene have recently been cloned and analyzed by CASEY (4) from S. carlsbergensis 244. The presence of two alleles suggests that chromosome $\mathrm{X}$ also exists in this yeast as a homologous/homeologous pair.

The production of vicinal diketone aroma compounds during wort fermentation, especially diacetyl and pentanedione, is of considerable importance to the brewing industry as consumers prefer low levels of these in beer (2). Diacetyl and pentanedione are not actually produced by brewers' yeast but are side-products of the isoleucine-valine pathway. Excess acetohydroxy acids formed by acetohydroxy acid synthase are excreted during the primary fermentation into the wort. A non-enzymatic oxidative decarboxylation follows with acetolactate being converted to diacetyl and acetohydroxybutyrate to pentanedione. A major reason for costly secondary fermentation in brewing is to reduce the levels of vicinal diketones during storage. A genetically engineered brewing yeast which produces low levels of these compounds would therefore be of great value to the brewing industry (34). In this publication, as part of an overall program at the Carlsberg Laboratory to genetically engineer lager yeast strains producing low levels of diacetyl, the isolation and analysis of two of three chromosomes $\mathrm{X}$ from $\mathrm{S}$. carlsbergensis 244 lager yeast is reported.

\section{MATERIALS AND METHODS}

\subsection{Strains and media}

All media used in this study have been described previously $(15,26)$. The strains of $S$. cerevisiae and $\mathrm{S}$. carlsbergensis employed throughout this study are listed in Table I. Figure 1 illustrates the crosses performed to construct the C85-0605 recipient and tester strains used in the isolation and analysis of chromosomes X.S. cerevisiae K5-5A was the source of the kar1-1 mutation and of the 7 chromosome $X$ markers in the starting strains all but $u$ ra 2 was in the final C85-0605 strains. The ura 2 marker was lost in the C84-0210 $\times$ C84-1010 crosses (Figure 1) as all C84-0411 progeny scored as wild-type $U R A 2$. Only later in the course of this study was it discovered that a psi factor was involved with this phenomenon as many C84-0411 clones originally scored as $U R A 2$ could be scored as ura 2 after 2 cycles of growth in the presence of 5 mM-guanidinium chloride. C84-0411-A64 and C84-0411-A33 were both subsequently found to be URA2. The linkage map for the six 


\section{G.P. CASEY: Chromosome $\mathrm{X}$ of carlsbergensis}

Table I. Yeast strains used in the study of chromosome $x$

S. carlsbergensis strains

244 Production lager brewing strain of Carlsberg Breweries

C80-CG7 Spore derived clone of 244, MAT?

(10)

C80-CG65 Spore derived clone of 244, MATa

C80-CG110 Spore derived clone of 244, MATa

S. cerevisiae strains used to construct tester and recipient 085-0605 strains

K5-5A MATa his4-594 ade2-10 can1 kar1-1

M607 MATa his4-594 ade2-40 trp5 lys1 cyh2

C82-0712-A30 MATa ura2 ade 1 rad

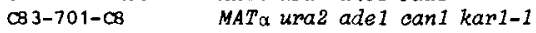

83-0701-C36 MAT $\alpha$ ura2 ade1 can1 kar1-1

084-3004-B23 MATa met3 ilv3 cyc1-1 cdc11 hom

084-3004-B35 MATa met3 ilv3 cycl-1 cde11 homb

C84-0108-17 MATa leu2-1 arg3

C84-0210-A1 MATa ura2 ade2-40 trp5 2ya1 cyh2 kar1-1

084-0210-B4 MATa uraz adez-40 lys1 oynz kart-1

084-1010-A35 MATa arg3 eyc1-1 cde11 homb

C84-0411-A33

MATa arg3 cyc1-1 ade2-40 trp5 lys1 cyh2 kar1-1

C84-0411-A64

MATa arg3 cyc1-1 hom6 ade2-40 lys1 cyh2 kar1-

C84-2812-A2

C84-2812-A9

MATa arg3 met3 ilv3 cyc1-1 cde11 hom6 ade1 trp5 cyh2

MATa arg3 ade2 -40 cyh2

C84-2812-A44 MATa met3 ilv3 cyc1-1 cdc11 hom6

084-2812-A61 MAT $\alpha$ arg3 hom6 ade2-40 lys1 cyh2 kar1-1

(5)

Carlsberg Laboratory

T. Nilsson-Tillgren

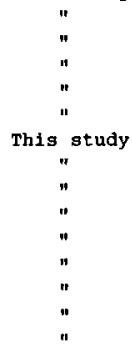

S. cerevisiae 085-0605 recipient strafns for chromosome $x$ transfer

C85-0605-A5 MATa arg3 met3 ilv3 cyc1-1 cde11 hom6 ade2-40 cyh2 kar1-1

85-0605-A10 MATa arg3 met3 ilv3 cyc1-1 ode11 hom6 ade2-40 lys1 ayh2 kar1-1

85-0605-A24 MAT $\alpha$ arg3 met3 ilv3 cyc1-1 ode11 homb ade2-40 oyh2 kar1-1

85-0605-B3 MAT $\alpha$ arg3 met3 ilv3 cye1-1 cde11 homb ade2-40 lys1 oyh2 kar1-1

085-0605-B21 MATa arg3 met3 ilv3 cyc1-1 ode11 hom6 ade2-40 oyh2 kar1-1

85-0605-B40 MATa arg3 met3 ilv3 cyc1-1 cde11 homb ade2-40 lys1 cyh2 kar1-1

S. cerevistae c85-0605 tester strains for chromosome $X$ analysis

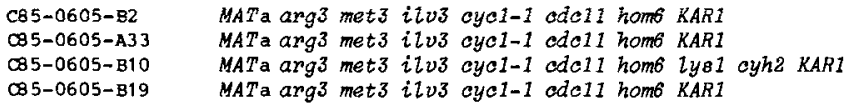

MATa arg3 met3 ilv3 cyc1-1 ode11 hom6 KARI

5. cerevisiae strains containing a $S$. carlsbergensis chromosome $X$ subjected to tetrad analysis

CB 5-0605-A16

CB5-0605-A29

C85-0605-C2

C85-0605-A5 with an additional chromosome $x$ from C80-CG7

085-0605-A5 with chromosome $X$ substituted with a chromosome $X$ from CBO-CG7

085-0605-B40 with chromosome $X$ substituted with a chromosome $X$ from C80-CG7

$085-0605-431$

085-0605-A10 with an additional chromosome $x$ from $080-0655$

S. cerevisiae strains containing a $S$. carlsbergensis chromosone $X$ which could not complement cyc1- 1 and for whtch there is no tetrad analysis data

C8 5-0605-A78

85-0605-A 148

C85-0605-E6

C85-0605- 818

$95-0605-C 48$

$085-0605-063$

$085-0605-085$

C85-0605- $\varnothing 7$

C85-0605-K12

C85-0605-L28

C85-0605-L98

C85-0605-L100

C85-0605-M13

$085-0605-M 27$

C85-0605-M36

C85-0605-M44

C85-0605-N 14

C85-0605-N20

C85-0605-A5 containing a $S$, carlsbergensis chromosome $X$ from C80-CG7

C85-0605-A10 containing a $S$. carlsbergensis chromosome X from C80-CG7

085-0605-840 containing a $\mathrm{s}$. carlgbergensis chromosome $\mathrm{X}$ from C80-CG7

C85-0605-B21 containing a S. carlsbergensis chromosome X from C80-CG110 C85-0605-A5 containing a S. carlsbergensis chromosome X from C80-C665

$"$

08-0605-A10 containing a S. carlsbergensis chromosome X from c80-CG65

"

C85-0605-A24 containing a $S$. carlsbergensis chromosome $X$ from C80-CG65

"

S. cerevisiae strains containing a $\mathrm{S}$. carlsbergensis chromosome $\mathrm{X}$ which can complement cyo1-1 and for which there is no tetrad analysis data

C85-0605-A1

C85-0605-A2

C85-0605-A6

C85-0605-A7

C85-0605-A11

C85-0605-A19

C85-0605-A24

CB5-0605-A27

C85-0605-A28

C85-0605-A33

C85-0605-A38

C85-0605-A39

1sersis chromosome $X$ from C80-CG7 


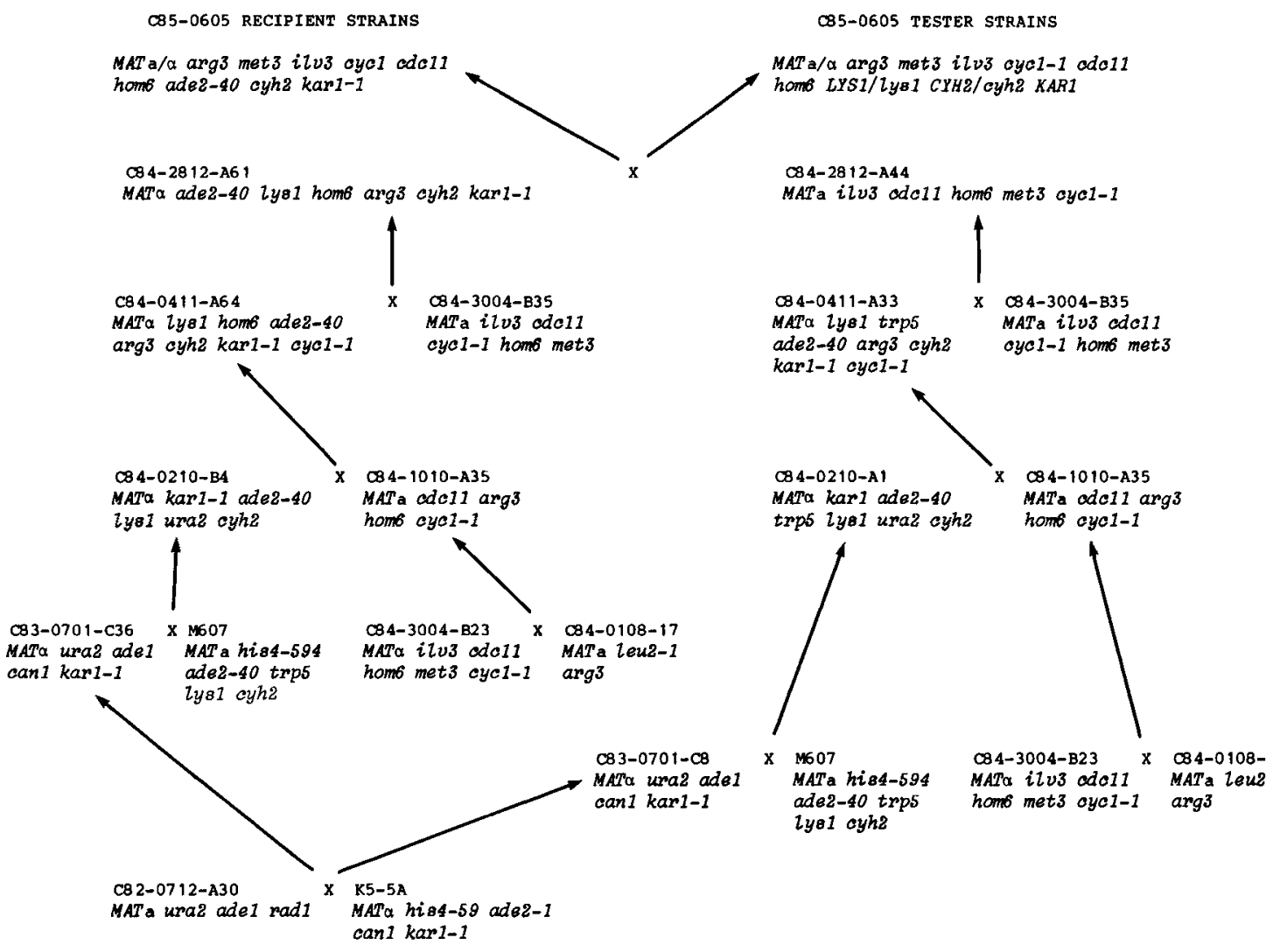

Figure 1. Crosses employed in the construction of S. cerevisiae C85-0605 recipient and tester strains.

markers in chromosome $\mathrm{X}$ of $\mathrm{S}$. cerevisiae is shown in Figure 2.

Map distances between the $\arg 3$ to $c d c 11$ chromosome X markers in the C85-0605 strains (Table II) were estimated by the formula of PERKINS (24) and are in good agreement with those published in the Edition 9 genetic map of Saccharomyces cerevisiae (18). In a separate cross between C84-2812-A2 (MATa ilv3 hom6 arg3 met3 cycl-1 cdcll trp5 ade1 cyh2) and C84-2812-A9 (MATa ade2-40 arg3 cyh2) the distance between the $c d c 11$ and hom6 loci was estimated at $43.8 \mathrm{cM}$ (PD:2, NPD:0, TT:14), compared to the reported distance of $37.5 \mathrm{cM}$ (18).

\subsection{Chromosome transfer protocol}

The mass mating technique used for chromosome transfer was based on the protocol of
JAKOB (13). Two strains of different mating type were grown to late log phase on YPD plates. Two loopfuls of each strain were then scraped off the surface of the plates and mixed with each other on a fresh YPD plate (several loops of sterile water were used to ensure homogenous mixing). The mass mating mixture was incubated at 30 ${ }^{\circ} \mathrm{C}$ for 4-6 hours followed by overnight incubation at $20^{\circ} \mathrm{C}$. The cells were then rinsed off the plate, washed twice with sterile water, and plated at a high density onto plates of selective media.

\subsection{Tetrad analysis and scoring of chromosome $\mathbf{X}$ markers}

Standard techniques were used for sporulation and tetrad analysis (11). The markers arg3, met $3, i l v 3$ and hom 6 were scored as the inability to grow at $30{ }^{\circ} \mathrm{C}$ on plates of SC-arginine, 


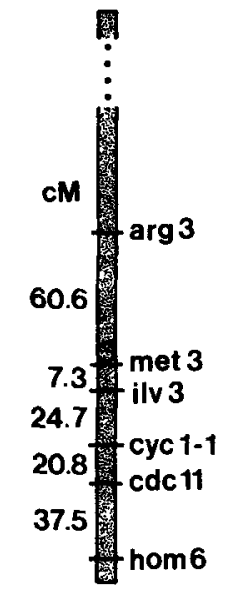

REFERENCE

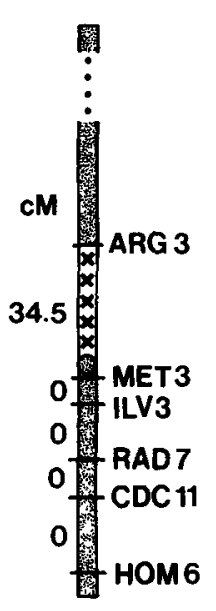

TYPE I

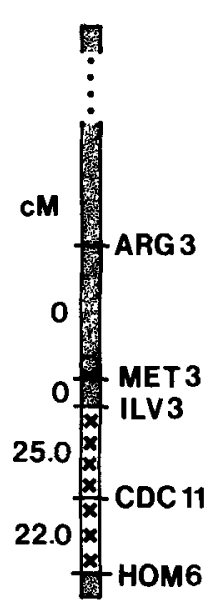

TYPE II
(S. cerevisiae)
(S. carlsbergensis)

Figure 2. Map of relevant markers of chromosome X in S. cerevisiae (18) and of type I and type II chromosomes $\mathrm{X}$ in $\mathrm{S}$. carlsbergensis. The regions in chromosome $\mathrm{X}$ of $\mathrm{S}$. carlsbergensis which recombine with the reference chromosome $\mathrm{X}$ of $\mathrm{S}$. cerevisiae are indicated by crosses.

SC-methionine, SC-isoleucine-valine and SCthreonine, respectively (while being able to grow on SC medium). The $c d c 11$ marker was scored as the inability to grow at $37^{\circ} \mathrm{C}$ on YPD plates (but being able to grow at $30^{\circ} \mathrm{C}$ on YPD). The cycl-1 marker is a deletion (31) covering the closely linked genes $C Y C l$ OSM1 RAD7 and was scored for the $\mathrm{rad} 7$ phenotype i.e. as the inability to grow on plates of YPD agar after 5 seconds exposure to UV light and incubation in the dark at $30^{\circ} \mathrm{C}$.

\subsection{Molecular hybridization analysis}

Extraction, cleavage, electrophoretic separation and transfer of DNA onto nitrocellulose paper were carried out following the protocol of MANIATIS et al. (17). Nick translation procedures and hybridization conditions were as described earlier (4). Filters containing hybridized probes were washed under conditions of high stringency (i.e. $68^{\circ} \mathrm{C}, 0.1 \times \mathrm{SSC}$ ) or low stringency (i.e. 60 ${ }^{\circ} \mathrm{C}, 3 \times \mathrm{SSC}$ ) depending on the nature of the probe and the experimental objective.

Table II. Tetrad analysis of the cross C84-2812-A61 (MATa ade2-40 lys1 hom6 arg3 cyh2 karl-1) $\mathrm{X}$ C84-2812-A44 (MATa ilv3 cdc11 hom6 met3 cyc1-1)

\begin{tabular}{lrrrrr}
\hline & PD & NPD & TT & $\begin{array}{l}\text { Calculated } \\
\text { Distances } \\
(\mathrm{cM})\end{array}$ & $\begin{array}{l}\text { Reported } \\
\text { Distances } \\
(\mathrm{cM})^{*}\end{array}$ \\
\hline arg3-met3 & 7 & 11 & 32 & 98 & 60.6 \\
met3-Ilv3 & 38 & 0 & 7 & 7.8 & 7.3 \\
ilv3-cycl-1 & 31 & 0 & 40 & 28.4 & 24.7 \\
cycl-1-cdc11 & 43 & 0 & 29 & 20.1 & 20.8 \\
\hline
\end{tabular}

*As reported in the genetic map, edition 9, of Saccharomyces cerevisiae (18) 


\begin{tabular}{|c|c|c|c|}
\hline $\begin{array}{l}\text { Bgl II - Sal } \\
\text { fragment } \\
\text { hybridizing }\end{array}$ & $\begin{array}{c}\text { Pattern I } \\
\text { DNA: S. cerevisiae } \\
\text { probe : (i) } 16-1 \\
\text { (high stringency) }\end{array}$ & $\begin{array}{c}\text { Pattern I + II } \\
\text { DNA: S.carlsbergensis } \\
\text { probe: (i) } 16-1 \\
\text { probe:(ii) 12-1 } \\
\text { (low stringency) }\end{array}$ & $\begin{array}{c}\text { Pattern II } \\
\text { DNA: S. carlsbergensis } \\
\text { probe : (ii) 12-1 } \\
\text { (high stringency) }\end{array}$ \\
\hline $6.8 \mathrm{~kb}$ & + & + & + \\
$3.9 \mathrm{~kb}$ & + & + & + \\
\hline $.9 \mathrm{~kb}$ & $+\mathrm{kb}$ & + & + \\
\hline
\end{tabular}

Figure 3. Diagnostic key to hybridization patterns with $I L V 3$ probes against BgllI-Sall restrictions of genomic DNA from S. cerevisiae and S. carlsbergensis. Probes 16-1 (i) and 12-1 (ii) are derived from two different alleles present in S. carlsbergensis.

\subsection{Preparation of genomic DNA}

Yeast genomic DNA was isolated based on the protocol of PEDERSEN (23). Stationary phase cells from $10 \mathrm{ml}$ of YPD medium were suspended in $1 \mathrm{ml}$ of $0.9 \mathrm{M}$-sorbitol, $0.1 \mathrm{M}$-EDTA pH 7.5, spun down at $15,000 \times \mathrm{g}$ and resuspended in 0.4 $\mathrm{ml}$ of $0.9 \mathrm{M}$-sorbitol, $0.1 \mathrm{M}$-EDTA and $14 \mathrm{mM}-\beta$ mercaptoethanol. Zymolase-60000 (from Arthrobacter luteus, Seikagaku Koygo Co. Ltd., Japan) was added $(0.2 \mathrm{mg}$ in $0.1 \mathrm{ml})$ and the mixture incubated at $37^{\circ} \mathrm{C}$ for 20-30 minutes. After spheroplast formation was complete the cells were resuspended in $0.4 \mathrm{ml}$ of TE and cell lysis induced by the addition of $90 \mu \mathrm{l}$ of 0.28 M-EDTA (pH 8.0), $0.4 \mathrm{M}$-Tris and 2.2\% SDS. After 30 minutes at $65^{\circ} \mathrm{C}, 80 \mu \mathrm{l}$ of $5 \mathrm{M}$-potassium acetate was added and the tube placed on ice for one hour. The tube was then spun for 15 minutes at 15,000 $\times$ g and the nucleic acids in the supernatant precipitated with ethanol. The resulting precipitate was resuspended in $0.5 \mathrm{ml}$ of $\mathrm{TE}$ and $25 \mu \mathrm{l}$ of $1 \mathrm{mg} / \mathrm{ml} \mathrm{RNase} \mathrm{(Sigma} \mathrm{R-5125)}$ added. This was then incubated at $38^{\circ} \mathrm{C}$ for 30 minutes followed by isopropanol precipitation of the DNA. The precipitate was then resuspended in $50 \mu \mathrm{l}$ of TE and 10-30 $\mu \mathrm{l}$ of this was used per restriction enzyme analysis of genomic DNA.

\section{6. $\mathrm{ILV} 3$ and $\mathrm{CYC1}$ gene probes used in the} molecular analysis of chromosome $X$

Two $I L V 3$ probes were used during the course of this study: (i) the $3.0 \mathrm{~kb}$ BamHI-EcoRI fragment from plasmid pGCT-16-1 and (ii) the $2.9 \mathrm{~kb}$ AvaI-Sall fragment from plasmid pGCT12-1 (4). Both fragments contain functionally complete alleles of $I L V 3$ which were cloned from S. carlsbergensis 244 by CASEY (4). On the basis of restriction site mapping and Southern analysis the $I L V 3$ allele from pGCT-16-1 is known to be identical to the allele of $I L V 3$ found in S. cerevisiae $\mathrm{S} 288 \mathrm{C}$ (4). The $I L V 3$ allele from pGCT-12-1, however, is unique to $S$. carlsbergensis and has an unrelated restriction site map. Each allele will only hybridize to the other under low stringency washing conditions (i.e. $60^{\circ} \mathrm{C}$, $3 \times \mathrm{SSC})$. At $68^{\circ} \mathrm{C} / 0.1 \times \mathrm{SSC}$ however, neither probe will hybridize to the other (4). In BglII-Sall digests of genomic DNA from S. cerevisiae $\mathrm{S} 288 \mathrm{C}$ and recipient $\mathrm{C} 85-0605$ yeasts both probes hybridize to 6.8 and $3.9 \mathrm{~kb}$ fragments (pattern I) under low stringency conditions (4). In BglII-Sall digests of genomic DNA from parental and spore derived clones of S. carlsbergensis 244 yeast both probes hybridize to 6.8 , $3.9,3.9$ and $1.6 \mathrm{~kb}$ fragments (pattern I and II) under low stringency conditions (4). At 68 
${ }^{\circ} \mathrm{C} / 0.1 \times \mathrm{SSC}$ however the $I L V 3$ probe from pGCT-12-1 remains hybridized to the 3.9 and $1.6 \mathrm{~kb}$ fragments containing the allele unique to the lager yeast (pattern II) while only the $I L V 3$ probe from pGCT-16-1 remains hybridized to the 6.8 and $3.9 \mathrm{~kb}$ fragments containing the allele shared between $S$. cerevisiae and the lager yeast (4). Figure 3 depicts the hybridization patterns for these two probes.

The $C Y C l$ probe used in this study was a 430 base pair Xhol fragment from the promoter region of $\mathrm{CYCl}$ which had been cloned from $\mathrm{S}$. cerevisiae. It was originally on the yeast-E. coli plasmid pRY65 (kindly provided by R. YOCUM, Biotechnica International, Cambridge, Mass.) and for the present study was sub-cloned before purification of the Xhol fragment for use as a probe. The fragment does not contain any BglIII, BamHI, EcoRI, SalI, XbaI, or HindIII cleavage sites.

To isolate $I L V 3$ and $C Y C I$ probes, restriction fragments were first isolated from $0.7 \%(w / v)$ agarose gels by electroelution onto a dialysis

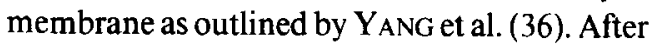
ethanol precipitation the fragments were purified and concentrated using the Elutip-d system (Schleicher and Schuell Inc.) TAE buffer (40 mM-Tris, $20 \mathrm{mM}$-acetate, $2 \mathrm{mM}-\mathrm{Na}_{2}$ EDTA, and $0.5 \mu \mathrm{g} / \mathrm{ml}$ ethidium bromide), $\mathrm{pH} 8.5$, was used as the electrophoresis buffer.

\subsection{Chromosome separation electrophoresis}

Electrophoresis apparatus and orthogonalfield-alternation gel electrophoresis conditions were set up according to CARLE and OLSON (3), while sample preparation and sample loading were based on the protocols of SCHWARTZ and CANTOR $(29,30)$ with the modifications described by PEDERSEN (22).

\section{RESULTS}

\subsection{Transfer of chromosome $X$ from spore derived clones of lager yeast $S$. carlsbergensis 244 to $S$. cerevisiae recipient strains}

Brewers' yeasts, normally unable to mate and produce viable spores, are not suitable candi- dates for chromosome transfer experiments (1, 9, 10). However, GJermansen and SigsgaARD (10) have sporulated the Carlsberg lager strain 244 and isolated viable spores exhibiting an a or $\alpha$ mating type (even though spore viability in general was extremely low). Three such meiotic segregants, C80-CG7, C80-CG65 and C80CG1 10 were each crossed with the recipient $S$. cerevisiae C85-0605 strains of the opposite mating type listed in Table I. Mating mixtures were densely plated on minimal medium containing cycloheximide and adenine in order to select for C85-0605 recipient cells that had received at least $A R G 3, M E T 3, I L V 3$, and HOM6 from the donor lager yeast (lysine was included in the selective medium for crosses involving lysl C85-0605 recipient strains). This medium does not permit the growth of either haploid parent or of true hybrids as the gene for cycloheximide resistance, $c y h 2$, is recessive. Red colonies arose at a frequency of $1-2 \times 10^{-6}$ per C85-0605 cell (white coloured colonies were discarded as they most probably represent normal diploids which by mitotic recombination in the cyh2 locus result in homozygosity for $c y h 2$ ).

Representative red colonies from each cross, which by virtue of their growth on this medium had received $A R G 3, M E T 3, I L V 3$, and HOM6 from the meiotic segregant of the lager yeast (but not $A D E 2$ or $C Y H 2$ ), were then scored for the other two chromosome $\mathrm{X}$ markers of interest. Surprisingly, while all were found to be $C D C 11$, clones derived from the same cross varied in the $R A D 7$ locus, scoring both as UV resistant and UV sensitive. This was true for crosses involving all three meiotic segregants of the lager yeast. Ten red colonies were then taken from each cross which retained the original mating type of the C85-0605 recipient strain and were not LYSI (to rule out co-transfer of chromosome IX). These were subsequently crossed with each of the tester S. cerevisiae C85-0605 strains of the opposite mating type listed in Table I and test dissections done on sporulated diploids in order to select for crosses yielding good spore viability. Four such crosses with high spore viability $(65 \%$ to $82 \%$ ) were selected for detailed analysis of chromosome $\mathrm{X}$ from the lager yeast. 
Table III. Tetrad analysis of the cross between chromosome $X$ transfer line C85-0605-A16 (MATa ARG3 MET3 ILV3 RAD7 CDC11 HOM6 ade2-40 cyh2 karl-1) and S. cerevisiae tester strain C85-0605-B2 (MATa arg3 met3 ilv3 cyc1-1 cdc11 hom6)

\begin{tabular}{|c|c|c|c|c|c|}
\hline & $4: 0$ & $3: 1$ & $2: 2$ & $1: 3$ & $0: 4$ \\
\hline$A R G 3 / \arg 3$ & & & 35 & 4 & \\
\hline$M E T 3 / m e t 3$ & & & 39 & & \\
\hline$I L V 3 / i l v 3$ & & & 39 & & \\
\hline$R A D 7 / c y c l-1$ & & & 39 & & \\
\hline$C D C 11 / c d c 11$ & & $1^{a}$ & 36 & $2^{\mathrm{a}}$ & \\
\hline \multirow[t]{2}{*}{ HOM6/hom6 } & & & 39 & & \\
\hline & PD & NPD & TT & Distance $(\mathrm{cM})^{*}$ & \\
\hline $\arg 3-m e t 3$ & 22 & 2 & 11 & $32.8 \mathrm{cM}$ & \\
\hline met3-ilv3 & 39 & 0 & 0 & -- & \\
\hline llv3-cycl-1 & 39 & 0 & 0 & - & \\
\hline$c y c 1-I-c d c 11$ & 37 & 0 & 0 & -- & \\
\hline cdcll-hom6 & 37 & 0 & 0 & -- & \\
\hline
\end{tabular}

a Interpreted to represent a meiotic gene conversion

* PeRKINS formula used to calculate distances underestimates distances above $40 \mathrm{cM}$ (24)

3.2. Tetrad analysis of recipient $\mathrm{S}$. cerevisiae C85-0605 strains containing a chromosome $X$ from $S$. carlsbergensis

The simultaneous transfer of $A R G 3, M E T 3$, ILV3, CDCII, and HOM6 suggested that most or all essential functions of chromosome $\mathrm{X}$ in $\mathrm{S}$. cerevisiae can be provided for by a single chromosome of S. carlsbergensis. As RAD7 was not transferred in certain cases it suggested the presence of possibly two different chromosome $X$ 's in the lager yeast. To ascertain if this was the case, and to determine the degree of homology

Table IV. Tetrad analysis of the cross between chromosome X transfer line C85-0605-A29 (MAT $\alpha$ ARG3 MET3 ILV 3 RAD 7 CDC11 HOM6 ade2-40 cyh2 karl-1) and S. cerevisiae tester strain C85-0605-A33 (MAT a arg3 met3 ilv3 cycl-1 cdc11 hom6)

\begin{tabular}{|c|c|c|c|c|c|}
\hline & $4: 0$ & $3: 1$ & $2: 2$ & $1: 3$ & $0: 4$ \\
\hline ARG3/arg3 & & & 25 & $1^{\mathrm{a}}$ & \\
\hline MET $3 /$ met 3 & & & 26 & & \\
\hline ILV3/ilv3 & & & 26 & & \\
\hline$R A D 7 / c y c l-1$ & & & 26 & & \\
\hline$C D C 11 / c d c 11$ & & & 26 & & \\
\hline \multirow[t]{2}{*}{ HOM6/hom6 } & & & 26 & & \\
\hline & $\mathrm{PD}$ & NPD & TT & Distance $(\mathrm{cM})^{*}$ & \\
\hline $\arg 3 \cdot \operatorname{met} 3$ & 12 & 0 & 13 & $26.0 \mathrm{cM}$ & \\
\hline met3-ilv3 & 26 & 0 & 0 & -- & \\
\hline $1 / v 3-c y c 1-1$ & 26 & 0 & 0 & -- & \\
\hline$c y c 1-1-c d c 11$ & 26 & 0 & 0 & -- & \\
\hline cdcll-hom6 & 26 & 0 & 0 & - & \\
\hline
\end{tabular}

a Interpreted to represent a meiotic gene conversion

* Perkins formula used to calculate distances underestimates distances above $40 \mathrm{cM}$ (24) 
Table V. Tetrad analysis of the cross between chromosome $X$ transfer line C85-0605-C2 (MAT $\alpha$ ARG3 MET3 ILV3 RAD7 CDC11 HOM6 ade2-40 cyh2 kar1-1) and S. cerevisiae tester strain C85-060585-B10 (MATa arg3 met3 ilv3 cyc1-1 cdc11 hom6)

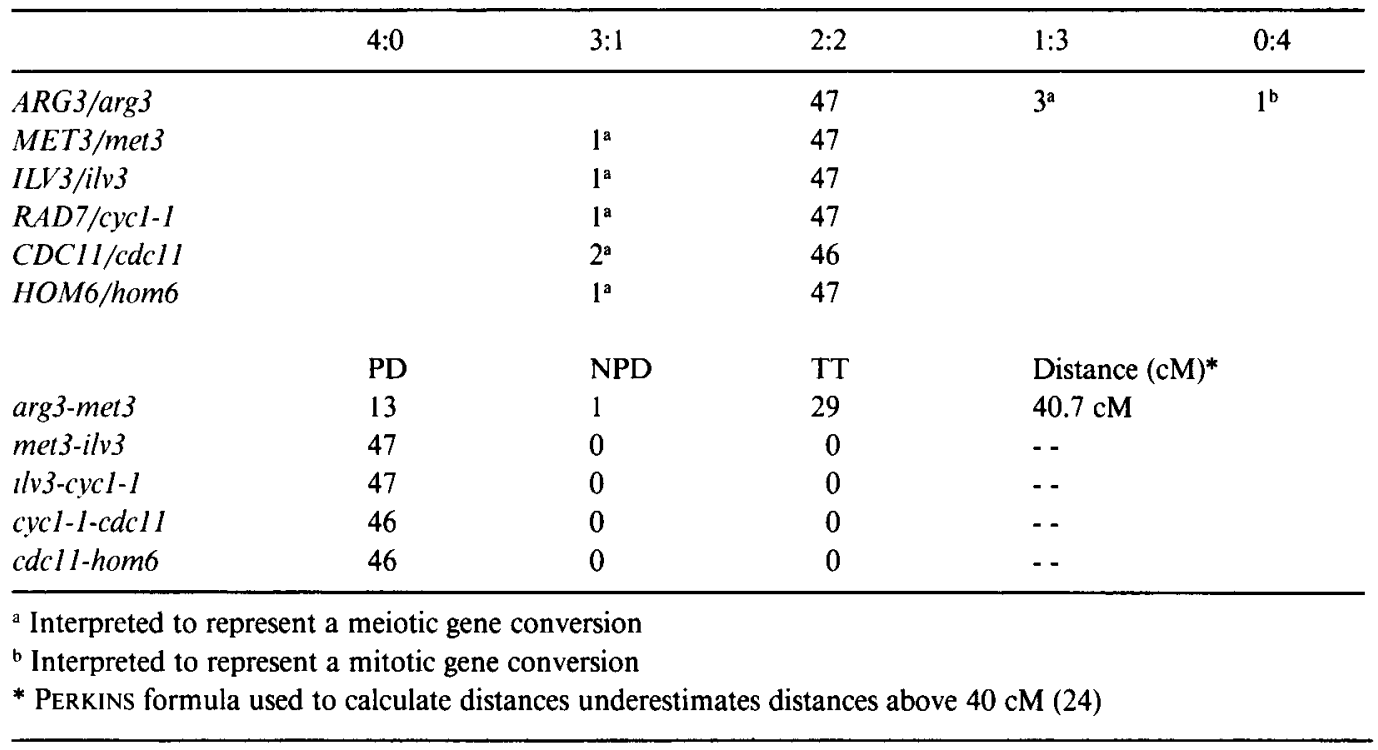

between chromosome $\mathrm{X}$ in $\mathrm{S}$. cerevisiae and $\mathrm{S}$. carlsbergensis lager yeast, recombination studies were carried out on crosses between tester $\mathbf{S}$. cerevisiae C85-0605 strains and four chromosome $\mathrm{X}$ transfer lines of C85-0605 (three of which were $R A D 7$ and one which was UV sensitive).

Tables III, IV, and V contain tetrad analysis data from crosses involving chromosome $\mathrm{X}$ transfer lines which received all chromosome $X$ markers from the lager yeast (namely C85-0605A 16, C85-0605-A29, and C85-0605-C2). In all three crosses a 2:2 segregation was seen for the six chromosome $X$ markers. From the linkage data (shown in the lower part of the tables) it can be seen that $A R G 3, M E T 3, I L V 3, R A D 7$, and $H O M 6$ are linked in the lager yeast chromosome involved in these crosses, confirming it to contain all of the essential functions of the markers tested in chromosome $\mathrm{X}$ from $\mathrm{S}$. cerevisiae. The structure of these chromosomes is quite different however as recombination between the chromosome $\mathrm{X}$ in the tester $\mathrm{C} 85-0605$ strains and the C85-0605 chromosome transfer lines was only observed between the $\arg 3$ and met 3 loci. All of the markers on the right arm segregated as if centromere linked and as recombination was only seen in the left arm for all three crosses it suggests that the chromosome transfer lines C85-0605-A16, C85-0605-A29, and C85-0605$\mathrm{C} 2$ contain the same chromosome $\mathrm{X}$ from the lager yeast. Distances between the arg3-met3 loci ranged from $26.0 \mathrm{cM}$ (Table IV) to $40.7 \mathrm{cM}$ (Table V), considerably shorter than the $60.6 \mathrm{cM}$ value reported in S. cerevisiae (18).

Tables VI and VII contain tetrad analysis data from crosses involving chromosome $\mathrm{X}$ transfer line C85-0605-M31 which received all chromosome $\mathrm{X}$ markers from lager yeast $\mathrm{C} 80-\mathrm{CG} 65$ except for RAD7. Examining Table VI first, it can be seen that the markers predominantly segregated 2:2 and that all of the chromosome X markers tested were linked. Once again recombination between the chromosomes $X$ of the tester and transfer strains was limited (suggesting different chromosome structure) but in this case recombination was only detected in the right arm of chromosome $\mathrm{X}$ (in the region spanning ilv3-hom6). Therefore, in terms of the loci contained, not only is the chromosome $\mathrm{X}$ from the lager yeast in C85-0605-M31 different from the chromosome $X$ in the other three chromosome transfer strains, but the recombination data reveal it to be different also in terms 
Table VI. Tetrad analysis of the cross between the UV sensitive chromosome X transfer line C85-0605-M31 (MAT $\alpha$ ARG3 MET3 ILV3 CDCII HOM6 ade2-40 cyh2 kar1-1) and S. cerevisiae tester strain C85-0605-B19 (MAT a arg3 met3 ilv3 cyc1-1 cdc11 hom6) from asci with four viable spores

\begin{tabular}{|c|c|c|c|c|c|}
\hline & $4: 0$ & $3: 1$ & $2: 2$ & $1: 3$ & $0: 4$ \\
\hline$A R G 3 / \arg 3$ & & & 29 & & \\
\hline MET3/met3 & & & 28 & $1^{a}$ & \\
\hline ILV3/ilv3 & & & 28 & $1^{\mathrm{a}}$ & \\
\hline$C D C l l / c d c I l$ & & & 26 & $3^{a}$ & \\
\hline \multirow[t]{2}{*}{ HOM6/hom6 } & & & 24 & 5 & \\
\hline & $\mathrm{PD}$ & NPD & $\mathrm{TT}$ & Distance $(\mathrm{cM})^{*}$ & \\
\hline arg3-met3 & 28 & 0 & 0 & -- & \\
\hline met3-llv3 & 28 & 0 & 0 & - - & \\
\hline ilv3-cdcll & 24 & 1 & 0 & $4 \mathrm{cM}$ & \\
\hline cdcll-hom6 & 17 & 0 & 5 & $11.4 \mathrm{cM}$ & \\
\hline
\end{tabular}

a Interpreted to represent a meiotic gene conversion

* Perkins formula used to calculate distances underestimates distances above $40 \mathrm{cM}$ (24)

Table VII. Tetrad analysis of the cross between the UV sensitive chromosome $X$ transfer line C85-0605-M31 (MAT $\alpha$ ARG3 MET3 ILV3 CDC11 HOM6 ade2-40 cyh2 karl-1) and S. cerevisiae tester strain C85-0605-B19 ( $M A T$ a arg3 met3 ilv3 cyc1-1 cdc11 hom6) from asci with three viable spores*

\begin{tabular}{lllcl}
\hline & PD & NPD & TT & Distance (cM)* \\
\hline arg3-met3 & 48 & 0 & 0 & - \\
met3-llv3 & 48 & 0 & 0 & - \\
ilv3-cdcll & 29 & 1 & 18 & $25.0 \mathrm{cM}$ \\
cdcll-hom6 & 31 & 2 & 13 & $27.2 \mathrm{cM}$ \\
\hline
\end{tabular}

* A 2:2 segregation was assumed

of the capacity for crossing over.

The high frequency of 1:3 segregation for HOM6:hom6 (17\%) and ARG3:arg3 (11\%) in the crosses involving C85-0605-M31 and C850605-A 16 respectively, indicate that these strains are chromosome addition lines. This notion was subsequently comfirmed for both of these strains by electrophoretic chromosome separation (cf. Figure 9).
A surprising observation during tetrad analysis of the C85-0605-M31 cross was that spores from asci in which only three of the spores were viable exhibited more extensive recombination in the ilv3-cdc11 and $c d c 11$-hom6 regions (Table VII) than in asci with four viable spores. It therefore would appear that recombination in this segment between the tester chromosome $X$ and the chromosome $\mathrm{X}$ of the lager yeast result-

Figure 4. Southern hybridization analysis of BglII-SalI cleaved genomic DNA under low $\left(60^{\circ} \mathrm{C}, 3 \times \mathrm{SSC}\right)$ and high $\left(68^{\circ} \mathrm{C}, 0.1 \times \mathrm{SSC}\right)$ stringency conditions when probed with the $I L V 3$ alleles of (a) pGCT-12-1 and (b) pGCT-16-1 . The same filter was used for both probes. Lane A, chromosome X substitution line C85-0605-C2; lane B, chromosome $X$ addition line C85-0605-A16; lane C, chromosome X substitution line C85-0605-A29; lane D, chromosome X addition line C85-0605-M31; lane E, S. carlsbergensis 244; lane F, S. cerevisiae C85-0605-B40; lane G, lambda-DNA cleaved with HindIII; lane H, lambda-DNA cleaved with EcoRI. 
a) (i) Low Stringency $\left(60^{\circ} \mathrm{C}, 3 \times \mathrm{SSC}\right)$

(ii) High Stringency $\left(68^{\circ} \mathrm{C}, 0.1 \times \mathrm{SSC}\right)$ $\begin{array}{llllllllllllllll}A & B & C & D & E & F & G & H & A & B & C & D & E & F & G & H\end{array}$

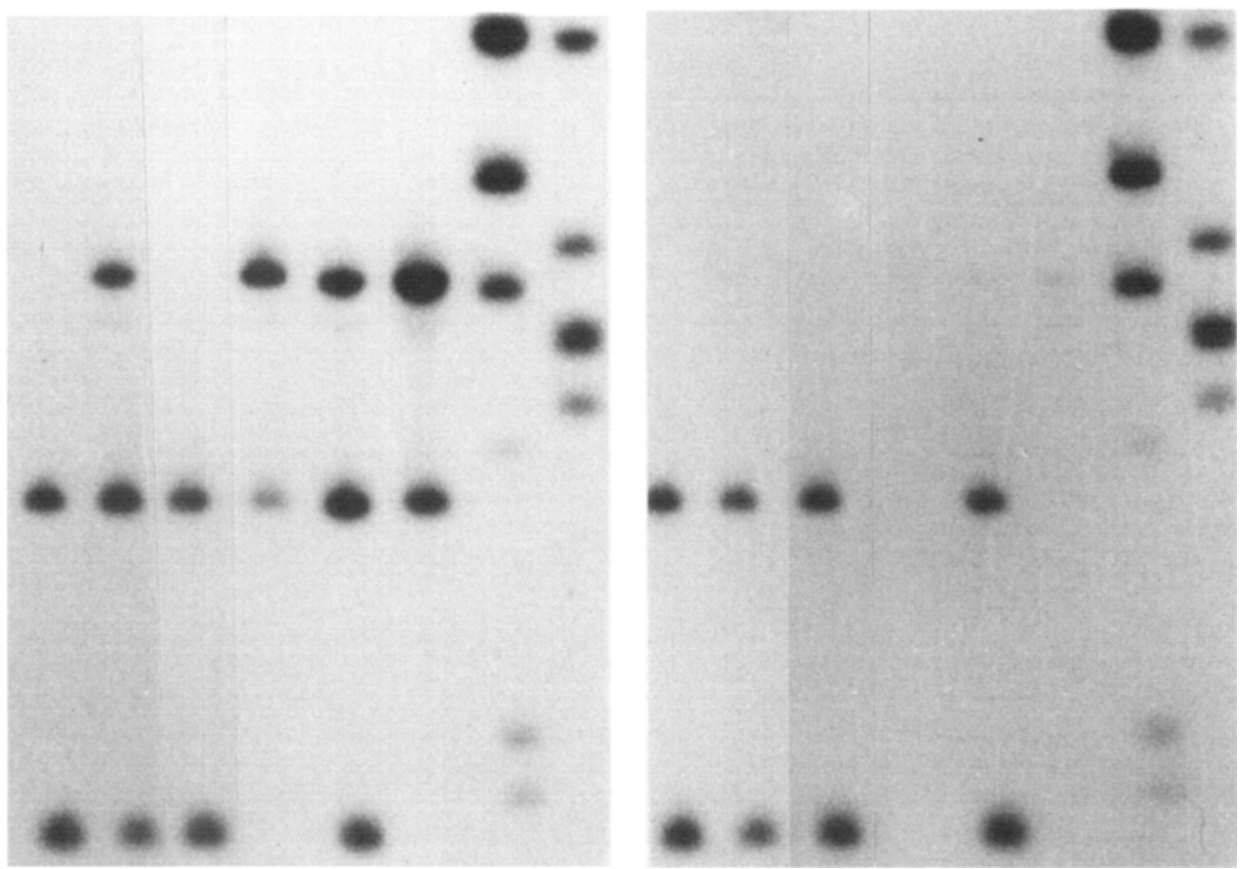

b) (i) Low Stringency $\left(60^{\circ} \mathrm{C}, 3 \times \mathrm{SSC}\right)$

(ii) High Stringency $\left(68^{\circ} \mathrm{C}, 0.1 \times \mathrm{SSC}\right)$

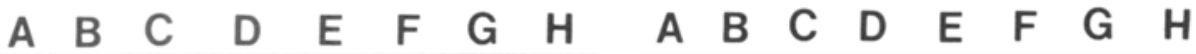

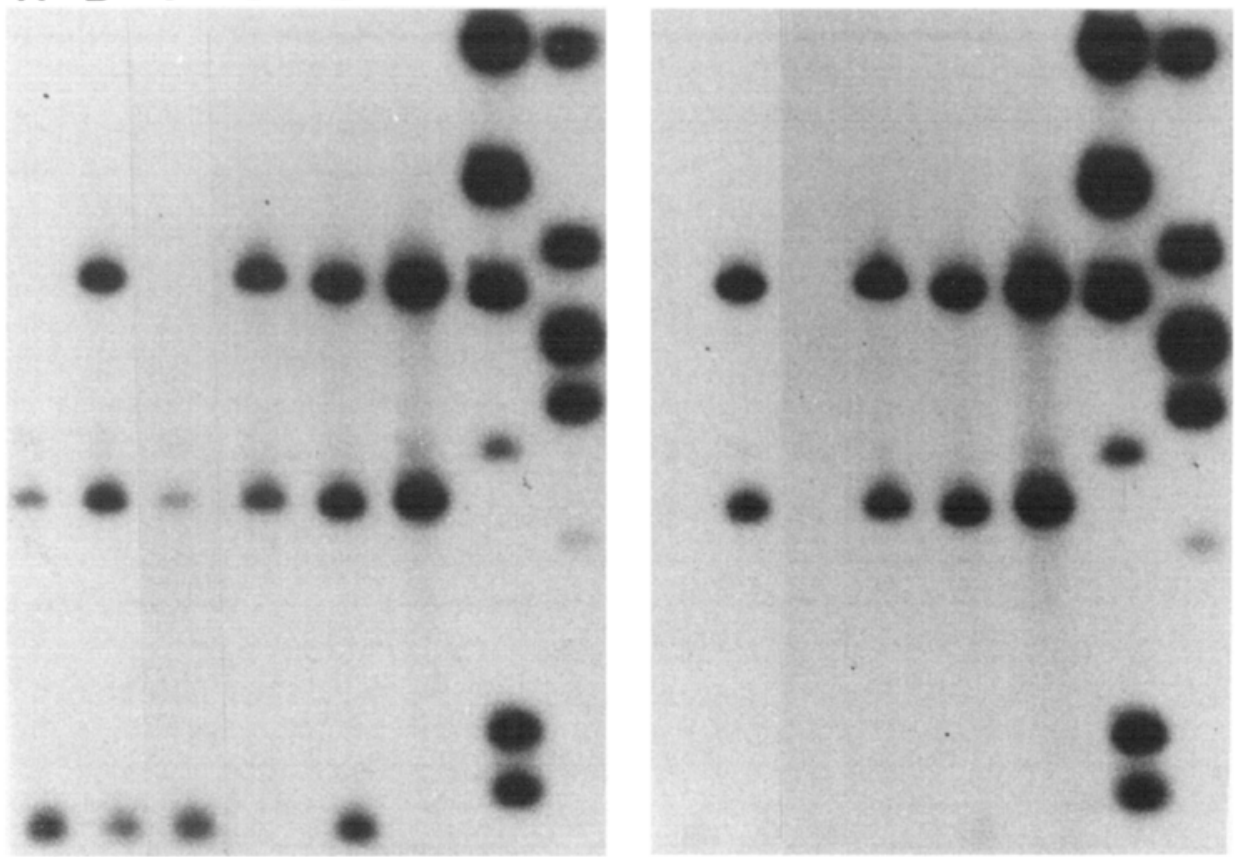


a) Low Stringency $\left(60^{\circ} \mathrm{C}, 3 \times \mathrm{SSC}\right)$

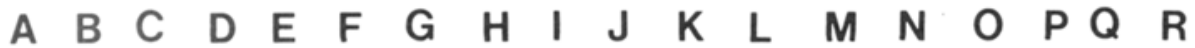

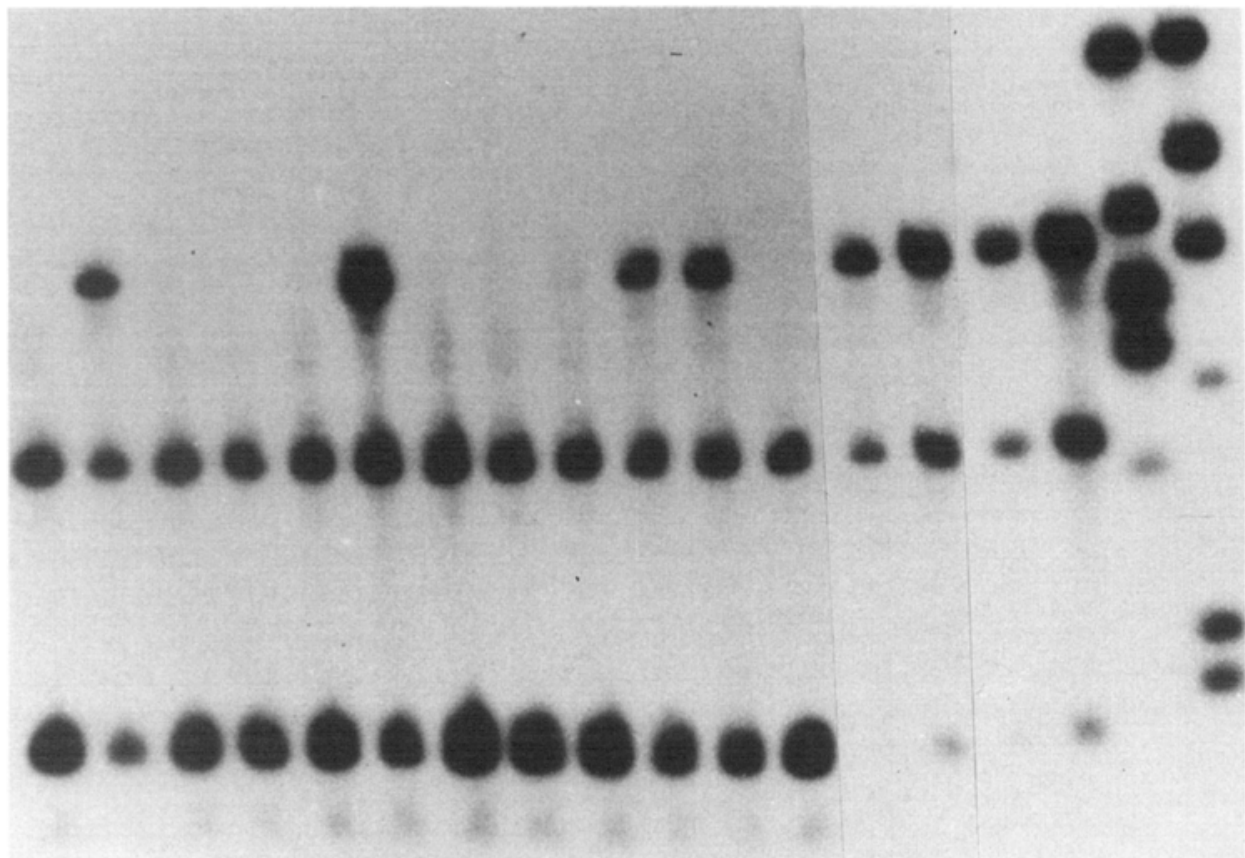

b) High Stringency $\left(68^{\circ} \mathrm{C}, 0.1 \times S S C\right)$

$\begin{array}{llllllllllllllllll}A & B & C & D & E & F & G & H & \text { I } & J & K & L & M & N & O & P & Q & R\end{array}$

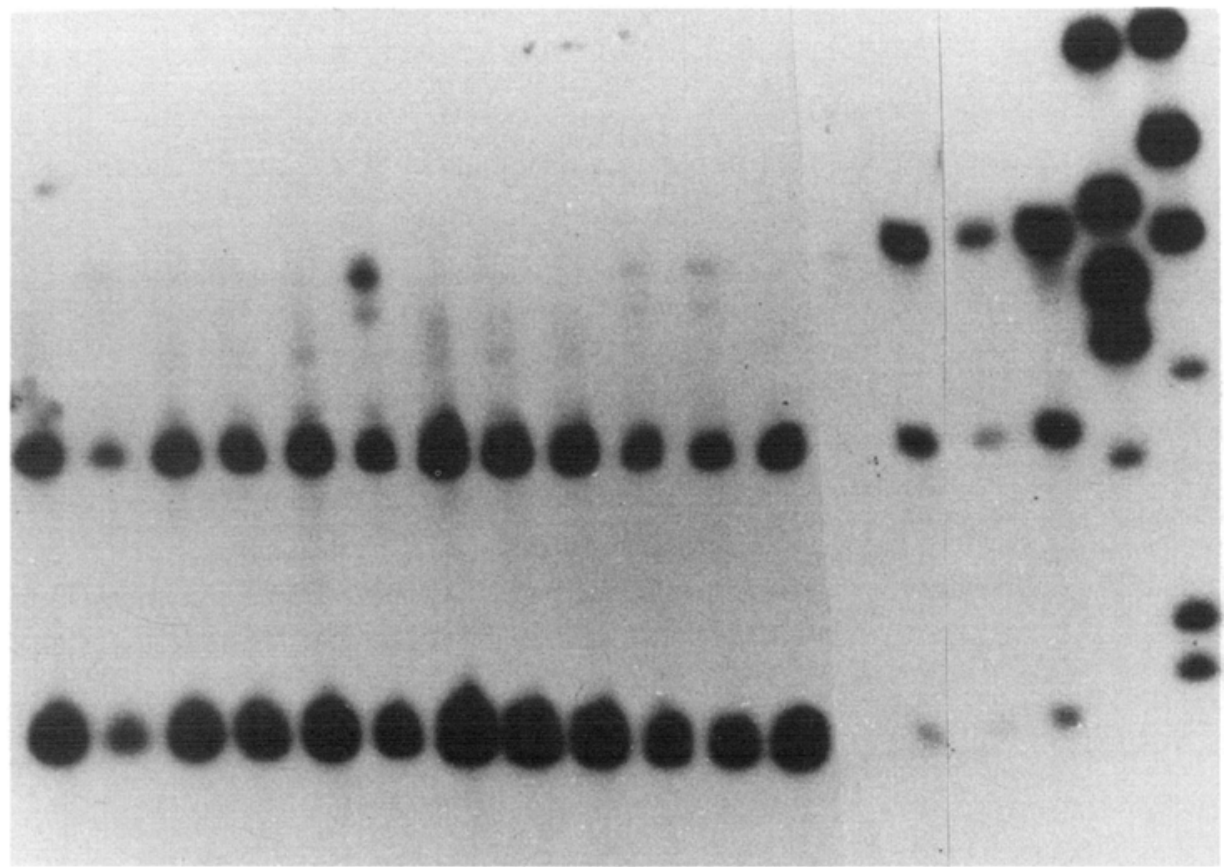


Figure 5. Southern hybridization analysis of BgllI-Sall cleaved genomic DNA from recipient S. cerevisiae C85-0605-A5 clones containing a S. carlsbergensis chromosome $X$ from C80-CG7 which can complement arg3 met $3 \mathrm{ilv} 3 \mathrm{rad} 7 \mathrm{cdcll}$ and hom 6 . The $I L V 3$ allele of pGCT-12-1 was used as a probe under (a) low $\left(60^{\circ} \mathrm{C}, 3 \times \mathrm{SSC}\right)$ and (b) high $\left(68^{\circ} \mathrm{C}, 0.1 \times \mathrm{SSC}\right)$ stringency conditions. Lanes A-L, C85-0605-A 1, 2, 6, 7, 11, 19, 24, 27, 28, 33, 38, and 39, respectively; lane M, C85-0605-A5; lane N, S. carlsbergensis 244; lane O, C80-CG65; lane P, C80-CG1 10; lane Q, HindIII cleaved lambda-DNA; lane R, EcoRI cleaved lambda-DNA.

ed in a chromatid making one spore being inviable. Further experiments are needed to clarify the genetic basis for this observation.

\subsection{Southern analysis of chromosome $X$ transfer lines C85-0605-A16, C85-0605-A29, C85-0605-C2, and C85-0605-M31 with $I L V 3$ gene probes cloned from the Carlsberg lager strain 244}

The genetic data in Tables III-VII indicates that there are at least two chromosomes X in S. carlsbergensis which not only differ considerably from chromosome $\mathrm{X}$ in $\mathrm{S}$. cerevisiae, but from each other as well. To obtain information on the degree of sequence homology between these chromosomes as regards the ILV 3 locus, as well as to determine if the genetically analyzed clones are substitution or addition lines, the four strains were probed with two $I L V 3$ gene probes from the parental lager strain (described in detail in the Materials and Methods, 2.5).

Figure 4 depicts Southern hybridization patterns of BglII-Sall digestions of genomic DNA from the four chromosome $X$ transfer lines (lanes A-D), the Carlsberg lager yeast strain (lane $\mathrm{E})$ and a reference recipient $\mathrm{S}$. cerevisiae strains (C85-0605-B40, lane F). The C85-0605-A29 and C85-0605-C2 strains exhibited pattern II hybridization (Figure 3 ) with the $I L V 3$ probes indicating that they are chromosome $\mathrm{X}$ substitution lines (the recipient C85-0605 strain exhibits pattern I with these probes). The C85-0605-A16 strain, however, is an addition line for chromosome $X$ as it exhibits both pattern I and II hybridization. Only strain C85-0605-M31 had a chromosome $\mathrm{X}$ which exhibited pattern I hybridization.

The results in Figure 4 indicate that when all chromosome $\mathrm{X}$ markers are transferred (i.e.
C85-0605-A16, C85-0605-A29, C85-0605-C2) the chromosome involved contains the allele of $I L V 3$ unique to the lager yeast (4). In the case of C85-0605-M31, however, where the UV sensitive phenotype of $c y c l-1$ was not complemented, the chromosome involved contained the allele of $I L V 3$ common to both $\mathrm{S}$. cerevisiae $\mathrm{S} 288 \mathrm{C}$ and the lager yeast. To determine if this observation remained valid under wider testing, genomic DNA preparations from a large number of chromosome $\mathrm{X}$ transfer lines, for which no tetrad analysis data was available, were probed with the two ILV 3 gene probes. Figure 5 examines twelve clones from cross C85-0605A5 $\times$ C80-CG7 (in which all chromosome $\mathrm{X}$ markers were transferred) probed with the

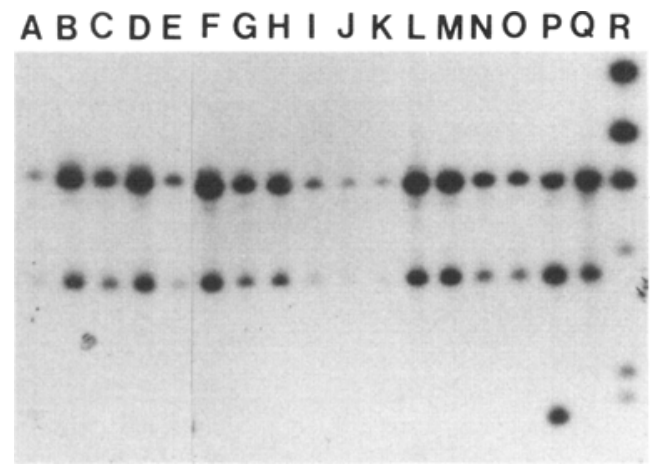

Figure 6. Southern hybridization analysis of genomic DNA from $S$. cerevisiae recipient strains containing a chromosome $\mathrm{X}$ from $\mathrm{S}$. carlsbergensis which could complement all chromosome $\mathrm{X}$ markers except for $\mathrm{rad} 7$. The probe was the $I L V 3$ allele found in pGCT$12-1$ and low stringency conditions were used $\left(60^{\circ} \mathrm{C}\right.$, $3 \times \mathrm{SSC}$ ). Lanes A-O are chromosome $\mathrm{X}$ transfer lines C85-0605-A78, -C48, -L100, -M44, -N14, -M13, -B6, -C63, -L28, -M27, -N20, -C87, -K12, -L98, and -M36, respectively. Lane $P, S$. carlsbergensis 244 . Lane $Q, S$. cerevisiae C85-0605-B40. Lane R, HindIII cleaved DNA. 
a) Low Stringency $\left(60^{\circ} \mathrm{C}, 3 \times \mathrm{SSC}\right)$

$\begin{array}{llllllllllllllllllll}A & B & C & D & E & F & G & H & \text { I } & J & K & L & M & N & O & P & Q & R & S & k b\end{array}$

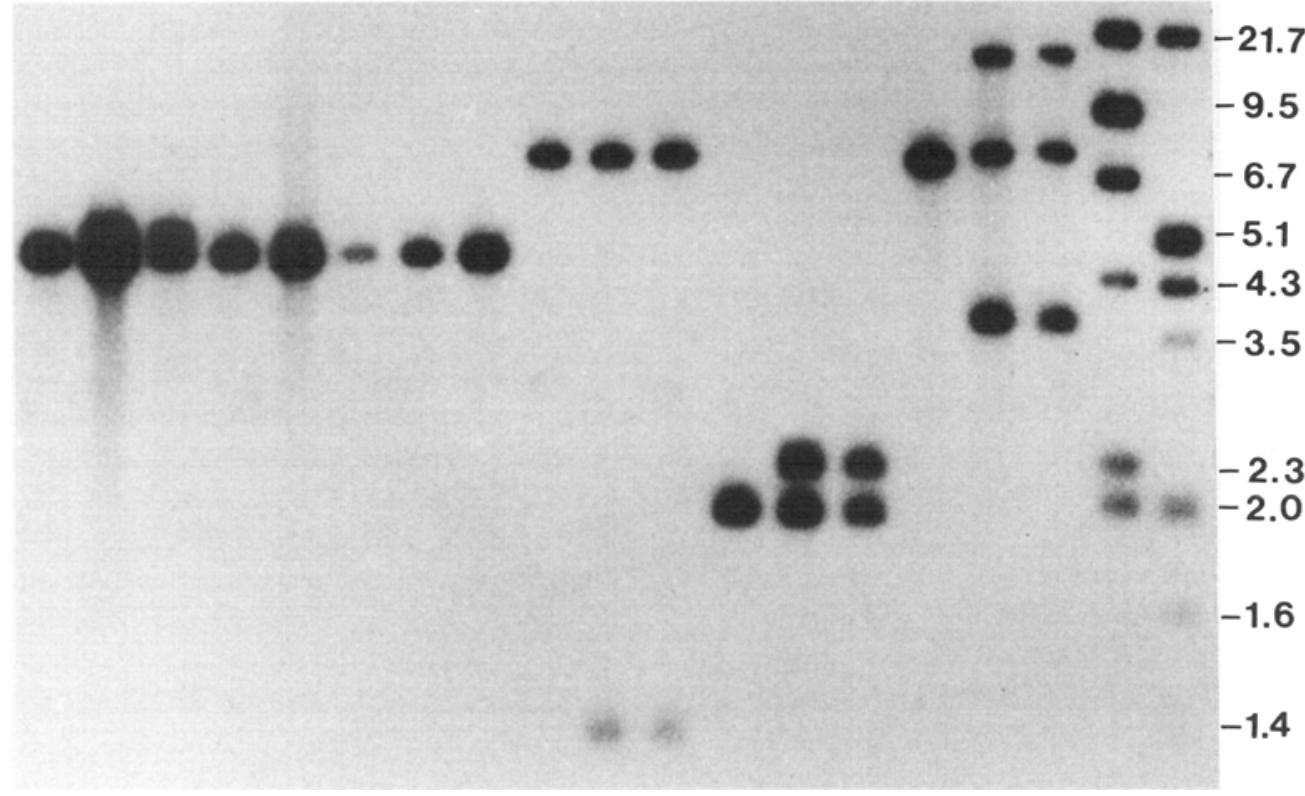

b) High Stringency $\left(68^{\circ} \mathrm{C}, 0.1 \times \mathrm{SSC}\right)$

$\begin{array}{llllllllllllllllllll}A & B & C & D & E & F & G & H & \text { I } & J & K & L & M & N & O & P & Q & R & S & k b\end{array}$

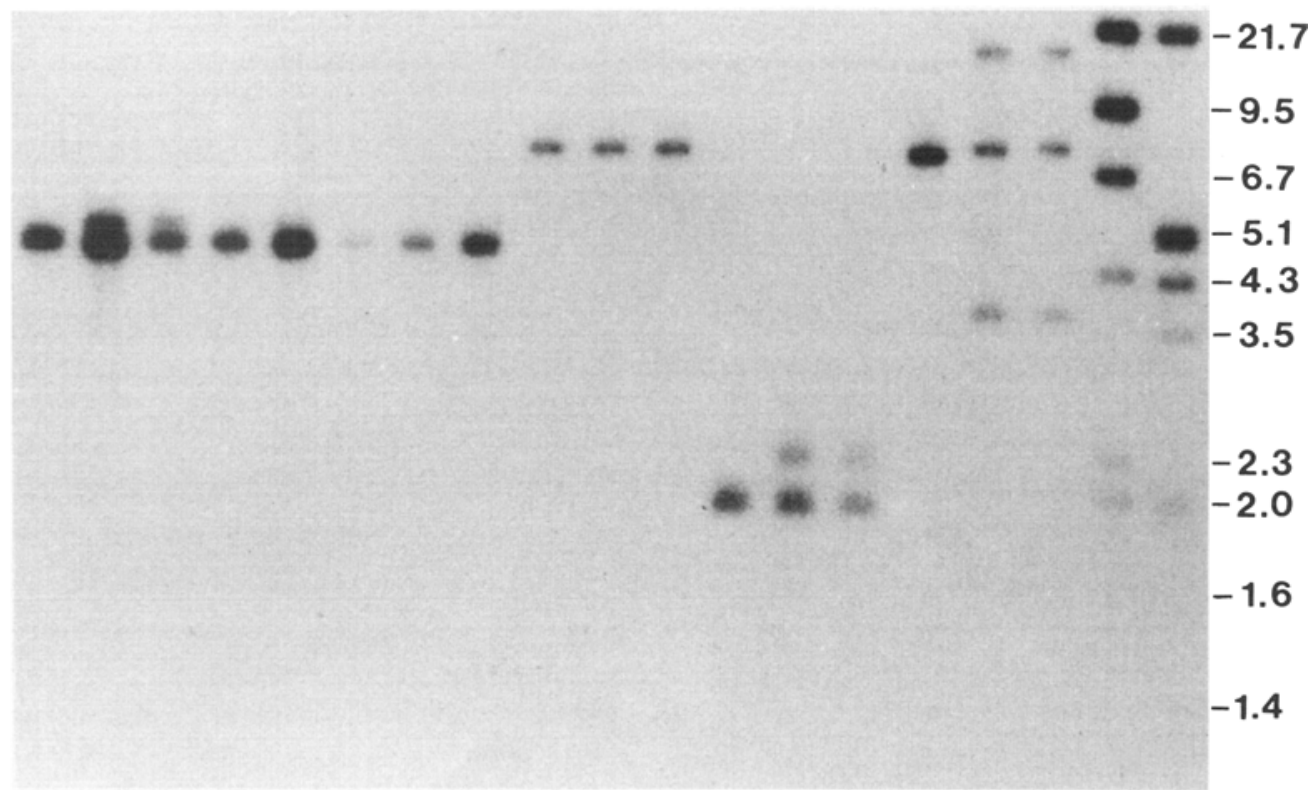


Figure 7. Southern hybridization analysis of S. cerevisiae S288C, S. carlsbergensis C80-CG7 and CG65 and S. cerevisiae C85-0605 lines with an acquired carlsbergensis chromosome $\mathrm{X}$ using a CYC1 gene probe from S. cerevisiae. Hybridization was carried out under (a) low stringency $\left(60^{\circ} \mathrm{C}, 3 \times \mathrm{SSC}\right)$ and (b) high stringency $\left(68^{\circ} \mathrm{C}\right.$, $0.1 \times \mathrm{SSC}$ ) conditions. Lanes A-H are BglII digests of genomic DNA from S. cerevisiae S288C, S. carlsbergensis C80-CG7, S. carlsbergensis C80-CG65 and chromosome X transfer lines C85-0605-C48, -C87, -M31 (chromosome $\mathrm{X}$ addition line), -M44, and -M13, respectively. Lanes I, J, and K; L, M, and N; O, P, and Q are EcoRI, SalI and Xbal digests of genomic DNA from S. cerevisiae S288C, S. carlsbergensis C80-CG7 and S. carlsbergensis C80-CG65, respectively. Lane R, HindIII cleavage of lambda-DNA, Lane S, EcoRI and HindIII cleavage of lambda-DNA.

pGCT-12-1 allele of $I L V 3$ which is unique to $\mathrm{S}$. carlsbergensis. Once again only pattern II hybridization was found under high stringency washing conditions (b) indicating that they all contain the chromosome $\mathrm{X}$ from the lager yeast containing the unique ILV3 allele. Chromosome $\mathrm{X}$ substitution occurred at a high frequency; eight of the twelve clones were substitution lines as they did not display pattern I + II hybridization under low stringency conditions (a). In Figure 6, 15 clones from crosses involving all three lager yeast meiotic segregants, but in which the $R A D 7$ marker was not transferred, were probed with $I L V 3$ from pGCT-12-1. As was seen in the case of C85-0605-M31, all fifteen exhibited pattern I hybridization under low stringency conditions, indicating that all had a chromosome $\mathrm{X}$ from the lager yeast containing the allele of $I L V 3$ common to both S. cerevisiae S288C and S. carlsbergensis. As the hybridization pattern of substitution and addition lines involving this type of chromosome $\mathrm{X}$ would be identical, it is not possible to reach any conclusions regarding the frequency of chromosome substitution.

\subsection{Southern analysis of the CYC1 locus on chromosome $\mathrm{X}$}

As the ability to complement the UV sensitive phenotype of the $c y c 1-1$ mutation was not transferred in C85-0605-M31 and in the clones depicted in Figure 6, the $\mathrm{CYCl}$ locus in several of these lines was compared with that in the lager yeast using a $\mathrm{CYCl}$ probe from $\mathrm{S}$. cerevisiae (Figure 7). Once again the lager yeasts were found to contain two alleles of a gene in chromosome $\mathrm{X}$ - one which is located on the same hybridizing fragments in BglII (lanes A-H),
EcoRI (lanes I-K), SalI (lanes L-N), and XbaI (lanes O-Q) digests of S. cerevisiae S288C DNA, and one which is unique to the lager yeasts. BglII digests of genomic DNA in Figure 7a reveals a hybridizing fragment of $4.5 \mathrm{~kb}$ that is common to S. cerevisiae S288C (lane A), C80-CG7 (lane B), C80-CG65 (lane C) and chromosome transfer lines C85-0605-C48, -C87, -M31, -M44, and -M13 (lanes D-H). The chromosome transfer lines lack the $4.8 \mathrm{~kb}$ fragment that is unique to the lager yeast i.e. only the chromosome $\mathrm{X}$ containing the $\mathrm{CYCl}$ allele in common with that found in S. cerevisiae was transferred into the clones which remained UV sensitive. This is consistent with earlier observations with ILV3 where only the chromosome containing the allele of $I L V 3$ in common with S. cerevisiae lacked $\mathrm{rad} 7$ complementing ability.

It is interesting to note that an $\mathrm{XbaI}$ site exists in the allele of $\mathrm{CYC}$ l that is unique to $\mathrm{C} 80-\mathrm{CG} 7$ and -CG65 (lanes P and Q, respectively). This shows differences in the nucleotide sequences of these two alleles. However, in general the degree of sequence homology is considerably higher in the $C Y C 1$ alleles than in the $I L V 3$ alleles as increasing the stringency of the washing conditions (Figure 7b) resulted in a much less noticeable decline in the hybridization intensity of the fragment unique to $S$. carlsbergensis than is seen with the $I L V 3$ alleles. The lack of $R A D 7$ in the $C Y C 1$ region of $\mathrm{S}$. carlsbergensis is accordingly not due to a deletion comparable with that of cyc1-1.

\subsection{Electrophoretic chromosome separation with chromosome $X$ transfer lines}

Based on tetrad analysis and Southern hybridization data in sections 3.2 and 3.3 it is not 


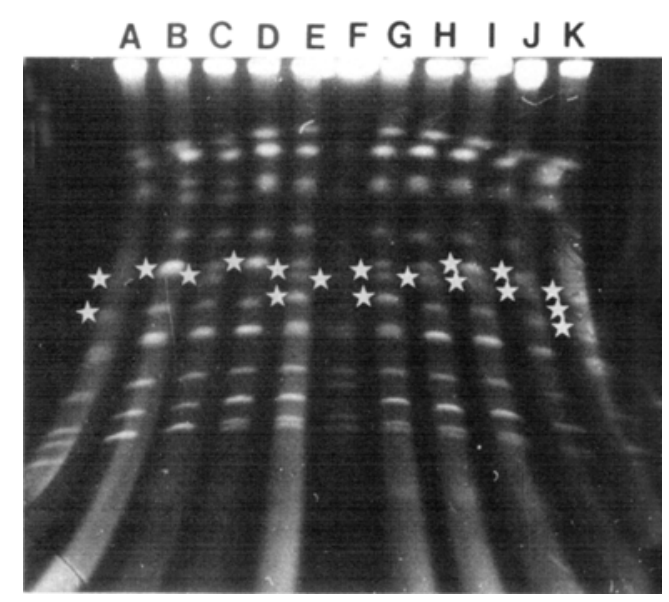

Figure 8. Photograph of a gel in which the chromosome sized DNA molecules of chromosome $\mathrm{X}$ addition and substitution lines were separated by field alternation electrophoresis. The autoradiographs of the gel probed with the two ILV3 alleles of S. carlsbergensis 244 are given in Figure 9. Lanes $A$ and $C$ are $S$. carlsbergensis C80-CG7 and S. cerevisiae C85-0605-B40, the donor and recipient strains respectively for the chromosome $X$ substitution line $\mathrm{S}$. cerevisiae $\mathrm{C} 85-0605-\mathrm{C} 2$ (lane $\mathrm{B}$ ). Lanes $\mathrm{D}$ and $\mathrm{I}$ are chromosome $\mathrm{X}$ substitution and addition lines S. cerevisiae C85-0605-A29 and -A16, respectively arising from the cross between $\mathrm{S}$. carlsbergensis C80-CG7 (lane A) and S. cerevisiae C85-0605A5 (lane $H$ ). Lanes $E$ and $G$ are chromosome $X$ addition lines $\mathrm{S}$. cerevisiae C85-0605-M31 (the strain in lane $G$ has a deeper red colony colour than the original isolate) arising from the cross between $\mathrm{S}$. carlsbergensis C80-CG65 (lane $\mathrm{K}$ ) and S. cerevisiae C85-0605-A10 (not shown). Lane F is S. cerevisiae $\mathrm{K} 5-5 \mathrm{~A}$, used as a reference strain to locate chromosome $\mathrm{X}$. Lane $\mathrm{J}$ is addition line C85-0605-A16 (also shown in lane I). Electrophoresis was carried out for 18 hours at $200 \mathrm{~mA}, 300 \mathrm{~V}, 5-8^{\circ} \mathrm{C}$ with a switching time of 50 seconds.

possible to conclude whether a clone is an addition or substitution line if it contains the chromosome $\mathrm{X}$ from $\mathrm{S}$. carlsbergensis lacking $R A D 7$. Southern analysis of blotted chromosome separations however does make it possible to reach such conclusions as depicted in Figures 8 and 9. Figure 8 is a photograph of the chromosome separation gel that was probed in Figure 9 with the two $I L V 3$ alleles of Carlsberg lager strain 244. In it, substitution clones C85-0605-C2 (lane B) and C85-0605-A29 (lane D) can clearly be seen to have substituted chromosome $X$ from the recipient C85-0605 strains (lanes $\mathrm{C}$ and $\mathrm{H}$, respectively) with a more slowly migrating chromosome $\mathrm{X}$ from C80-CG7 (lane A). The addition line C85-0605-A16, however, (lane I) has two chromosomes which hybridize to the $I L V 3$ probes under low stringency conditions - the original chromosome $\mathrm{X}$ from the recipient (lane $\mathrm{H})$ and the more slowly migrating chromosome $\mathrm{X}$ of $\mathrm{C80-CG7}$. These results confirm the earlier speculation that these three chromosome transfer lines contain the same chromosome $X$ from S. carlsbergensis C80-CG7. The strong degree of hybridization of the $I L V 3$ probe from pGCT-121 to these lines under high stringency conditions (Figure 4) also confirms that this chromosome contains the allele of $I L V 3$ unique to S. carlsbergensis. It is worthwhile to note that chromosome $\mathrm{X}$ was the only chromosome transferred from the lager yeasts in these crosses. The chromosome profile of the addition and substitution lines only differs at the chromosome $\mathrm{X}$ location, with no new bands or doublets being observed (relative to the original recipient $\mathbf{S}$. cerevisiae C85-0605 strains).

In the case of the C85-0605-M31 strain, however, a different chromosome $\mathrm{X}$ was transferred from the lager yeast (as predicted from the genetic and Southern data). Lanes $E$ and $G$ depict C85-0605-M31 (the isolate in lane G had a deeper red colony colour than that in lane $\mathrm{E}$ ) and in this case a more rapidly migrating chromosome X (donated from C80-CG65, lane K) had been transferred to the recipient C85-0605A 10 strain (not shown). As C85-0605-M31 contains two hybridizing chromosomes at low stringency conditions, it can now be concluded to be an addition line for chromosome $X$. This chromosome, lacking $R A D 7$, contains the allele of $I L V 3$ that is found in $\mathrm{S}$. cerevisiae yeast as only the $I L V 3$ probe from pGCT-16-1 remains bound to this chromosome under high stringency washing conditions (Figure $9 b$ ).

A surprising observation in Figure 9 is that lager yeast C80-CG65 has three chromosomes which hybridize to the $I L V 3$ probes under low stringency conditions. C80-CG7, however, only has two, suggesting that these meiotic segregants differ in their genetic composition. It also indi- 
a)

ILV 3 from $\mathrm{pGCT}-12-1$

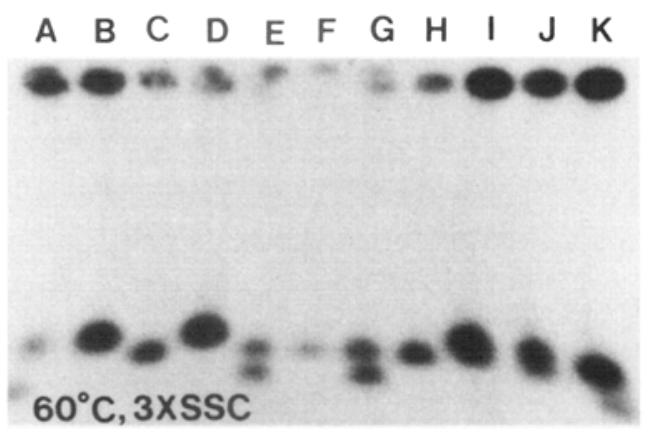

A $B$ B C D E

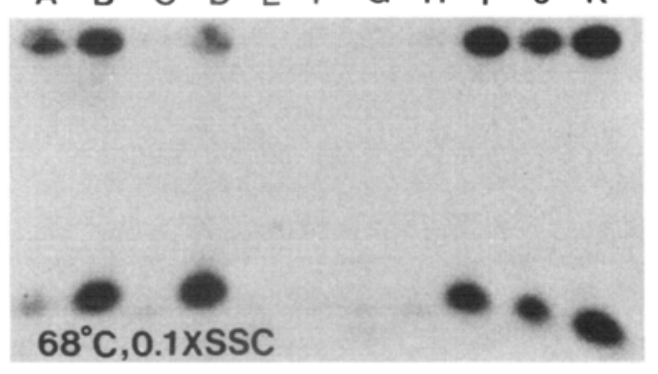

b) ILV 3 from $\mathrm{pGCT}-16-1$

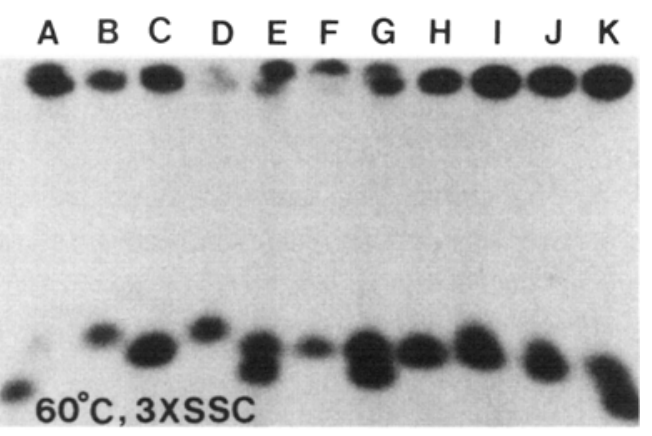

A B C D E F G

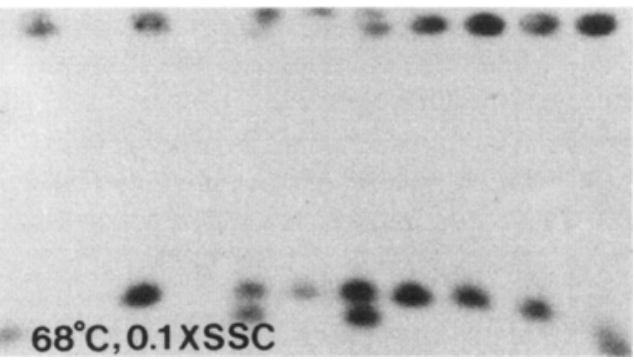

Figure 9. Southern hybridization analysis of the gel with the electrophoretically separated chromosomes shown in Figure 8 . The probes used were the ILV3 allele of pGCT-12-1 (a) and pGCT-16-1 (b) under low $\left(60^{\circ} \mathrm{C}, 3 \times \mathrm{SSC}\right)$ and high $\left(68^{\circ} \mathrm{C}, 0.1 \times \mathrm{SSC}\right)$ stringency conditions. Lane designations are the same as those used in Figure 8 . The same filter was used for both $I L V 3$ probes.

cates that the parental S. carlsbergensis 244 lager strain is trisomic for chromosome $\mathrm{X}$. This idea was confirmed in a later chromosome separation experiment (Figure 10) where a Southern analysis of the $S$. carlsbergensis 244 parent strain (lane D) and C80-CG110 and C80-CG65 meiotic segregants (lanes $A$ and $B$ ) clearly reveals the presence of three hybridizing chromosomes $\mathrm{X}$. It is therefore apparent that the middle migrating chromosome $\mathrm{X}$ has yet to be isolated and analyzed in the background of a $S$. cerevisiae recipient strain.

\section{DISCUSSION}

The relatively new technique of chromosome separation electrophoresis is a powerful tool for industrial mycologists as it is now possible to visualize yeast chromosomes in a gel and, by utilizing gene probes for specific chromosomes, determine chromosome ploidy. This report presents direct evidence that lager brewing yeasts are heteroploid. While brewing yeasts were widely believed to be polyploid $(7,16,28,32)$, the evidence used to support these claims has largely been indirect or based on techniques known to be difficult to interpret, e.g. on the basis of segregation of mating and sporulation phenotype (7) or measurement of DNA content per cell $(16,28,32)$.

Using the ILV 3 alleles of $\mathrm{S}$. carlsbergensis (Carlsberg lager strain 244) as chromosome probes, this lager strain was shown to be trisomic for chromosome $\mathrm{X}$ (assuming no co-migration of an additional chromosome $\mathrm{X}$ ). The three chromosomes migrate independently of each other during chromosome separation electrophoresis and two of these have been isolated 


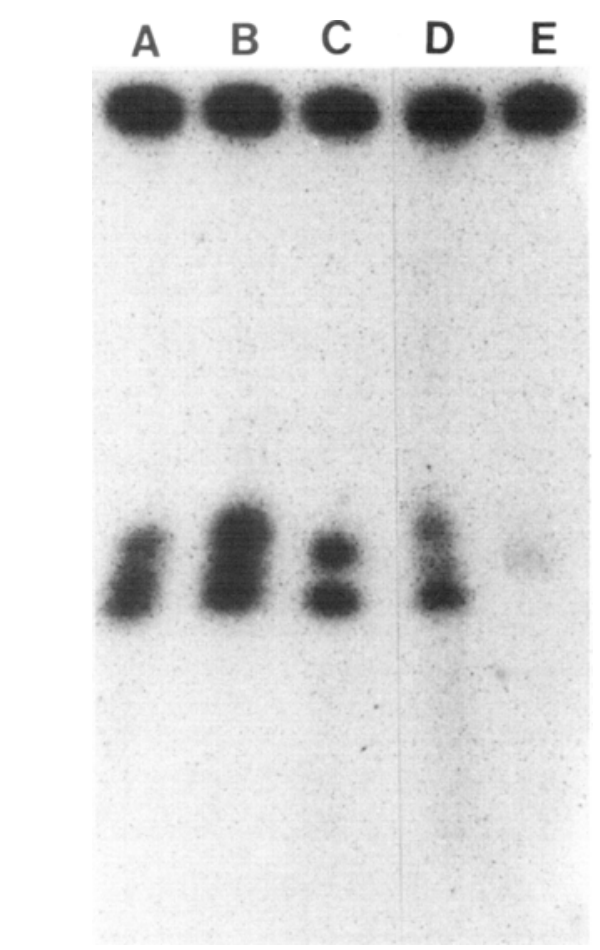

Figure 10. Southern hybridization analysis of chromosome blots probed with the $I L V 3$ allele of pGCT-12-1 under low stringency conditions. Lane A, S. carlsbergensis C80-CG110; lane $B, S$. carlsbergensis C80CG65; lane C, S. cerevisiae C85-0605-M31; lane D, S. carlsbergensis 244; lane E, S. cerevisiae K5-5A.

and analyzed in the genetic background of $S$. cerevisiae. Type I chromosome X migrates more slowly than the reference chromosome $\mathrm{X}$ of $\mathrm{S}$. cerevisiae K5-5A and contains the allele of $I L V 3$ unique to the lager yeast. It can recombine with chromosome $\mathrm{X}$ from $\mathrm{S}$. cerevisiae, but only in the left arm. Type II chromosome X migrates faster than the chromosome $\mathrm{X}$ of $\mathrm{S}$. cerevisiae $\mathrm{K} 5-5 \mathrm{~A}$ and contains the allele of $I L V 3$ that is shared between the lager yeast and $\mathrm{S}$. cerevisiae S288C. It also can recombine with chromosome $\mathrm{X}$ from $\mathrm{S}$. cerevisiae, but in this case only in the right arm of chromosome X. Both type I and type II chromosomes $\mathrm{X}$ are different homeologues of chromosome $\mathrm{X}$ when compared with that of $S$. cerevisiae. A similar situation has been found with chromosomes III and V from this yeast $(19,21,34)$, but with chromosomes XII and XIII both homologues and homeologues to the corresponding chromosomes in S. cerevisiae have been reported (34). It is interesting to note however that type III chromosome $\mathrm{X}$ in the lager yeast co-migrates with chromosome $\mathrm{X}$ from the reference S. cerevisiae K5-5A yeast. Efforts are currently under way to isolate and analyze this chromosome in order to determine if it is homologous to the chromosome $\mathrm{X}$ of S. cerevisiae (as S. carlsbergensis 244 seems to contain only two alleles of $I L V 3$ (4) this chromosome is not expected to contain a novel allele of ILV3). It will also be interesting to conduct electrophoretic chromosome separation and molecular hybridization experiments involving chromosomes III, V, XII, and XIII in order to determine if a third type exists for these chromosomes as well.

Carlsberg lager strain 244 exhibits the normal properties of lager brewing yeasts which makes their genetic manipulation difficult i.e. poor mating ability, poor sporulation and poor spore viability (10). The production of aneuploid spores, which would result in poor spore viability (7), can now be concluded to contribute to these properties as spore derived clones from this yeast were found to be either disomic (as in C80-CG7) or trisomic (as in C80-CG65 and -CG110) for chromosome $X$. The demonstrated nucleotide sequence inhomology between the different types of chromosome $\mathrm{X}$ will also contribute to these properties as recombination is a prerequisite for proper disjunction of chromosomes in meiosis. Ultimately, it is hoped that by increasing our understanding of the genetic composition of lager yeast sophisticated breeding programs can be facilitated.

\section{ACKNOWLEDGEMENTS}

I wish to express my gratitude to the following persons for their contribution to this work. Claes Guermansen, Steen Holmberg, Morten Kielland-Brandt, Mogens B. Pedersen, Jens G. Litske Petersen, Julio Polaina, Torsten Nilsson-Tillgren, and Diter VON WETTSTEIN for stimulating discussions during the course of this work. GITTE BANK. KIRSTEN SCHULTZ and LOTTE VAA for excellent technical assistance. Mogens B. Pedersen for his assistance in the electrophoretic chromo- 
some separation experiments. ANN-SOFI STEINHOLTZ and NINA RASMUSSEN for preparing the figures. The author was supported by a Canadian government administered NSERC postdoctoral fellowship.

\section{REFERENCES}

1. ANDERSON, E \& P. A. MARTIN: The sporulation and mating of brewing yeast. J. Inst. Brew. 81, 242-247 (1975)

2. Cabane, B., C Ramos-Jeunehomme, N LAPAge \& C A MASSCHELEIN: Vicinal diketones - the problem and prospective solutions. Amer. Soc. Brew. Chem. Proc. 1973. pp. 94-99 (1974)

3. CARle, G F. \& M. V. Olson: An electrophoretic karyotype for yeast. Proc. Natl. Acad. Sci. 82, 3756-3760 (1985)

4. CASEY, G P.: Cloning and analysis of two alleles of the $I L V 3$ gene from Saccharomyces carlsbergensis. Carlsberg Res. Commun. 51, 327-341 (1986)

5. CondE. J. \& G R. FINK: A mutant of Saccharomyces cerevisiae defective for nuclear fusion. Proc. Nat. Acad. Sci. USA 73, 3651-3655 (1976)

6. DUTCHER, S. K : Internuclear transfer of genetic information in karl-I/KARI heterokaryons in Saccharomyces cerevisiae. Molec. Cell Biol. 1, 245-253 (1981)

7. EMEIS. C. C.: Polyploide Kulturhefen. Eur. Brew. Conv. Congr. Wien, 205-215 (1961)

8. Falco.S C.K.S. Dumas \& K. J. Livak: Nucleotide sequence of the yeast $I L V 2$ gene which encodes acetolactate synthase. Nucl. Acids Res. 13, 4011 4027 (1985)

9. Fowell, R R.: Sporulation and hybridization of yeasts. In: The Yeasts. A. H. Rose \& J. Harrison, eds., Academic Press, London and New York, Vol. I, pp. 303-383 (1969)

10. GJeRMANSEN.C \& P SigsGaARD: Construction of a hybrid brewing strain of Saccharomyces carlsbergensis by mating of meiotic segregants. Carlsberg Res. Commun. 46, 1-11 (1981)

11. Hawthorne. D. C. \& R. K. Mortimer: Chromosome mapping in Saccharomyces: Centromerelinked genes. Genetics 45, 1085-1110 (1960)

12. Holmberg, S.: Genetic differences between Saccharomyces carlsbergensis and $\mathrm{S}$. cerevisiae II. Restriction endonuclease analysis of genes in chromosome III. Carlsberg Res. Commun. 47, 233-244 (1982)

13. JАKOB, H:: Technique de synchronisation de la formation des zygotes chez la levure Saccharomyces cerevisiae. Compt. Rend. Hebd. Seanc. Acad. Sci., Paris 254, 3909-3911 (1962)
14. Johnston, J. R.: Breeding yeasts for brewing, II. Production of hybrid strains. J. Inst. Brew. 71, 135-137 (1965)

15. Kielland-Brandt, M C., T Nilsson-Tillgren.S. Holmberg, J.G. L. Petersen \& B. A. SvenNingsen: Transformation of yeast without the use of foreign DNA. Carisberg Res. Commun. 44, 77-87 (1979)

16. Lewis, C W, J. R. Johnston \& P A. Martin: The genetics of yeast flocculation. J. Inst. Brew. 82 , 158-160 (1976)

17. Maniatis, T., E.F Fritsch \& J Sambrook: Molecular cloning. A laboratory manual. Cold Spring Harbor Laboratory (1982)

18. Mortimer, R K. \& D SCHILD: Genetic map of Saccharomyces cerevisiae, Edition 9. Microbial. Rev. 49, 181-212 (1985)

19. Nilsson-Tillgren. T, C. Gjermansen, M. Kielland-Brandt, J G. L. Petersen \& S. Holmberg: Genetic differences between Saccharomyces carlsbergensis and S. cerevisiae. Analysis of chromosome III by single chromosome transfer. Carlsberg Res. Commun. 46, 65-76 (1981)

20. Nilsson-Tillgren, T., M.C Kielland.Brandt,S. Holmberg. J.G. L Petersen \& C Giermansen: Is lager yeast a species hybrid? Utilization of intrinsic genetic variation in breeding. Proc. IV Internat. Symp. Genet. Industr. Microorg. Kyoto, pp. 143147 (1982)

21. Nilsson-Tillgren. T., J. G. L Petersen, S HolmBERG \& M. C. KIELLAND-BRANDT: Transfer of chromosome III during kar mediated cytoduction in yeast. Carlsberg Res. Commun. 45, 113-117 (1980)

22. Pedersen, M. B.: DNA sequence polymorphisms in the genus Saccharomyces III. Restriction endonuclease fragment patterns of chromosomal regions in brewing and other yeast strains. Carlsberg Res. Commun. 51, 163-168 (1986)

23. Pedersen, M. B.: DNA sequence polymorphisms in the genus Saccharomyces. I. Comparison of the $H I S 4$ and ribosomal RNA genes in lager strains, ale strains and various species. Carlsberg Res. Commun. 48, 485-503 (1983)

24. Perkins, D. D : Biochemical mutants in the smut fungus Ustilago maydis. Genetics $34,1,607-626$ (1949)

25. Petersen, J G. L., S. Holmberg, T. Nilsson-TillGREN \& M. C. KIELLAND-BRANDT: Molecular cloning and characterization of the threonine deaminase (ILVI) gene of Saccharomyces cerevisiae. Carlsberg Res. Commun. 48, 149-159 (1983)

26. Petersen, J. G. L. M. C. Kielland-Brandt, S Holmberg \& T. Nilsson-Tillgren: Mutational analysis of isoleucine-valine biosynthesis in Sac- 
charomyces cerevisiae. Mapping of $i l v 2$ and ilv5. Carlsberg Res. Commun. 48, 21-34 (1983)

27. Polaina, J.: Cloning of the ILV2,ILV3 and ILV 5 genes of Saccharomyces cerevisiae. Carlsberg Res. Commun. 49, 577-584 (1984)

28. RUSSELL, I. \& G. G. STEWART: Spheroplast fusion of brewer's yeast strains. J. Inst. Brew. 85, 95-98 (1979)

29. Schwartz, D C., W. Saffran, J Welsh, R. Haas, M. Goldenberg \& C. R. CANTOR: New techniques for purifying large DNAs and studying their properties and packaging. Cold Spring Harbor Symp. Quant. Biol. 47, 189-195 (1982)

30. SChwartz, D. C. \& C. R CANTOR: Separation of yeast chromosome-sized DNAs by pulsed field gradient gel electrophoresis. Cell 37, 67-75 (1984)

31. Singh, A. \& F. Sherman: Deletion of the iso-1-cytochrome $c$ and adjacent genes of yeast: Discovery of the $O S M 1$ gene controlling osmotic sensitivity. Genetics 89, 653-665 (1978)
32. StewART, G. G., I RuSSEll \& T. GoRING: Naturenurture anomalies - further studies in yeast flocculation. Am. Soc. Brew. Chem. Proc. 33, 137-147 (1975)

33. ThORNE, R.S. W.: The genetics of flocculence in Saccharomyces cerevisiae. Compt. Rend. Lab. Carlsberg, Ser. Physiol. 25, 101-140 (1951)

34. Wettstein, D. von, C. GJermansen, S. Holmberg, M C. Kielland-Brandt, T. Nilsson-Tillgren, M. B. Pedersen, J. G. L. Petersen \& P. Sigsgaard: Genetic engineering in the improvement of brewers yeast. MBAA Tech. Quart. 21, 45-61 (1984)

35. WINGE, $O$ : On segregation and mutation in yeast. Compt. Rend. Lab. Carlsberg, Ser. Physiol. 24, 79-96 (1944)

36. YANG, R. C. A., J. LIS \& R. WU: Elution of DNA from agarose gels after electrophoresis. In: Methods in Enzymology, R. Wu, ed. Academic Press, New York, Vol. 68, pp. 179-182 (1979)

Accepted by E. LuND 